\title{
Biogenesis and secretion of exosomes
}

Joanna Kowal 1, 2, ${ }^{*}$, Mercedes Tkach ${ }^{1,2,{ }^{*}}$, Clotilde Théry ${ }^{1,2,3}$

${ }^{1}$ Institut Curie, Centre de Recherche, 26 rue d'Ulm, Paris, F-75248 France;

${ }^{2}$ INSERM U932, Paris F-75248, France

3Paris Sciences et Lettres (PSL*), Paris F-75005.

*: equal contribution

corresponding author: clotilde.thery@curie.fr;

INSERM U932, Institut Curie, 26 rue d'Ulm, 75248 Paris cedex 05, France tel: 33156246716

\section{Abstract:}

Although observed for several decades, the release of membrane-enclosed vesicles by cells into their surrounding environment has been the subject of increasing interest in the past few years, which led to the creation, in 2012 , of a scientific society dedicated to the subject: the International Society for Extracellular Vesicles. Convincing evidence that vesicles allow exchange of complex information fuelled this rise in interest. But it has also become clear that different types of secreted vesicles co-exist, with different intracellular origins and modes of formation, and thus probably different compositions and functions. Exosomes are one sub-type of secreted vesicles. They form inside eukaryotic cells in multivesicular compartments, and are secreted when these compartments fuse with the plasma membrane. Interestingly, different families of molecules have been shown to allow intracellular formation of exosomes and 
their subsequent secretion, which suggests that even among exosomes different sub-types exist.

\section{Highlights:}

ESCRT proteins, lipids and tetraspanins can independently generate intraluminal vesicles

Different RAB proteins can target multivesicular compartments to the plasma membrane

Vesicles with different densities, and probably different origins, are co-secreted

\section{Keywords:}

extracellular vesicles, exosomes, microparticles, microvesicles, RAB, SNARE, ESCRT, lipids, tetraspanins

\section{Abbreviations:}

DC: dendritic cell; ESCRT: endosomal sorting complex required for transport; EV: extracellular vesicle; ILV: intraluminal vesicle; LBPA: lysobisphosphatidic acid; MHC: Major Histocompatibility Complex; MVB: multivesicular body; PLP: proteolipid protein; PLD2: phospholipase D2; PM: plasma membrane; SNARE: Soluble NSF-Attachment Protein Receptor; TFR: Transferrin Receptor.

Note: Official gene and protein symbols were generally used, with protein symbols written in uppercase letter (e.g. RAB27A) independently of the species studied (mouse, human etc.) (www.informatics.jax.org/mgihome/nomen). 


\section{Introduction: the discovery of exosomes}

The release of membrane-enclosed vesicles from tumor cells and platelets $[1,2]$, possibly explaining observations of extracellular vesicles (EVs) within tissues [3] or body fluids [1,4] was described more than 40 years ago. Originally, these EVs were thought to bud directly from the plasma membrane (PM). In the 1980's, however, two groups studying reticulocyte maturation described a more complex mode of EV secretion. They showed that small vesicles were formed by inward budding inside an intracellular endosome, leading to the formation of a multivesicular body (MVB), which could then fuse with the PM and release outside its internal vesicles [5,6] (Figure 1). In 1987, the word "exosomes" was proposed for these EVs of endosomal origin [7] (Box 1). The existence of this unusual EV secretion pathway was confirmed afterwards in, among others, antigen-presenting cells [8,9], epithelial cells [10] and tumour cells [11]. Further description of mRNA and miRNA in exosomes [12] sparked a strong interest in these vesicles. Since mRNA had also been shown in PM-derived microvesicles [13], it is currently believed that cells use EVs as a mean of extracellular communication and exchange of proteins, lipids and nucleic acids [14]. Whether exosomes and other EVs display different or identical functions is, however, still unclear. Answering this question will become possible from a detailed knowledge of the cell biology of these vesicles, which should provide targets to specifically affect their production in vivo. This review will summarize the recent advances on the molecular machineries of exosome formation and secretion, but interested readers can refer to our more detailed review also discussing the other types of EVs [15].

\section{Exosome composition}

Initial proteomic studies revealed that exosomes contain a specific subset of proteins from endosomes, the PM and the cytosol [16], but very few from other intracellular organelles (nucleus, mitochondria, Golgi). This confirmed that exosomes represent a specific subcellular compartment, since they do not contain a random set of proteins, as would be the case for cell debris. These observations were validated in numerous other studies of the protein 
composition of exosomes, and recently of other EVs, which have been made accessible through the creation of two specific databases compiling published data: Vesiclepedia [17] and EVpedia [18]. Of note, although exosomes should be enriched in endosomal components, as compared to PM-derived EVs, the two types of EVs display a large overlap in composition, and it is not possible today to name universal (i.e. valid for any cell type) protein markers specific for exosomes versus PM-derived vesicles.

Interestingly, although investigations of the lipid composition of exosomes were not as frequent as proteomic analyses, all studies showed differences with whole cell membranes [19-24]. Exosomes are enriched in cholesterol, sphingomyelin, ceramide and phosphatidylserine, but not in lysobisphosphatidic acid (LBPA), a lipid described in MVBs' intraluminal vesicles (ILVs) [25]. Some of these lipids (e.g. sphingomyelin and cholesterol) and some exosomal proteins (e.g. GPI-anchored proteins and flotillins) are also enriched in detergent-resistant subdomains of the PM called lipid rafts [26]. Indeed, a direct link between endocytosis of lipid rafts and eventual secretion into exosomes has recently been shown in mesenchymal stem cells [27].

These analyses of exosome composition unravelled the presence of molecules or families of molecules, which could be involved in their formation inside MVBs, or in their release outside the cell. We will thus now discuss the current knowledge of exosome biogenesis and in particular their formation as ILVs in MVBs and their secretion requiring the transport and fusion of MVBs with the PM.

\section{Exosome biogenesis: formation of ILVs in endosomal compartments}

MVBs, which appear along the endocytic pathway, are characterized by the presence of vesicles in their lumen (i.e. ILVs) formed by inward budding from the limiting membrane [28] (Figure 1). The molecular mechanisms of ILV formation have been extensively studied, especially in yeast [29], but we will describe here only the studies analysing these molecules in the context of exosome release, as summarized in Table 1.

\section{a) ESCRT-machinery}


Description of the Endosomal Sorting Complex Required for Transport (ESCRT) machinery involved in the formation of ILVs began in the early 2000's [30], and has been widely reviewed lately in the literature [29,31]. ESCRT consists of 4 complexes plus associated proteins: ESCRT-0 is responsible for cargo clustering in a ubiquitin-dependent manner, ESCRT-I and -II induce bud formation, ESCRT-III drives vesicle scission, and the accessory proteins (especially the VPS4 ATPase) allow dissociation and recycling of the ESCRT machinery. Members of the ESCRT family, TSG101 and ALIX (gene name: Pdcd6ip), were found in our first extensive proteomic analysis of mouse dendritic cell (DC)-derived exosomes, even before they were known to belong to this machinery [16]. Identification of ESCRT components in exosomes was further confirmed and extended by others (see EVpedia: www.evpedia.info; Vesiclepedia: www.microvesicles.org).

Four independent studies have shown a requirement for the ESCRT-0 member HRS in exosome secretion, demonstrated by a decrease in exosome secretion upon HRS inhibition in various cell types: HeLa cells [32], mouse DCs (but only after incubation with a antigen)[33], HEK293 [34] and head and neck squamous cell carcinoma [35]. In addition, in our shRNA-based screen performed in HeLa cells expressing the Major Histocompatibility Complex (MHC) class II machinery of antigen presentation (HeLa-CIITA), depletion of the STAM1 ESCRT-0 component also reduced exosome secretion [32].

Depletion of TSG101, an ESCRT-I component, also lead to reduced exosome secretion in the tumour cells HeLa-CIITA [32], MCF-7 [36], and in immortalized RPE1 epithelial cells [37], but not in the oli-neu oligodendroglial cells, where another ESCRT-independent mechanism was described (see below) [22].

Members of the ESCRT-II and ESCRT-III complexes are consistently found in proteomic analyses of various exosomes (see Vesiclepedia and EVpedia). In our shRNA screen, we did not observe a clear influence of ESCRT-II proteins on exosome secretion by HeLa-CIITA cells, and technical issues prevented conclusions on ESCRT-III components [32]. In the MCF-7 cell line, however, depletion by RNAi of each isoform of CHMP4, separately or simultaneously, decreased exosome secretion [36]. 
The ESCRT-III-associated protein ALIX was recently shown to promote intraluminal budding of vesicles in endosomes and hence exosome biogenesis, upon interaction with syntenin, the cytoplasmic adaptor of heparan sulphate proteoglycan receptors [36]. In HeLa-CIITA cells, depletion of ALIX caused an increase of MHC class II molecules in the cells and consequently in the released vesicles, without a clear effect on the amount of exosomes secreted, while in primary DCs silencing of ALIX decreased secretion of CD63, CD81 and MHC class II positive vesicles in half of the donors [32]. In a muscle cell line, ALIX depletion promoted an increased release of PM-derived EVs containing HSC70 but decreased secretion of CD63 (a tetraspanin enriched in late MVBs, hence in exosomes) [38].

VPS4 is involved at the final steps of ILV formation - i.e. scission of a membrane and/or dissociation of the ESCRT-III complex [31]. Data concerning its impact on exosome biogenesis seem contradictory: in our hands, shRNA inhibition of VPS4B in HeLa-CIITA cells increased exosome secretion [32], while a decrease in exosome secretion was observed in MCF-7 upon simultaneous silencing of VPS4A and VPS4B, with no significant effect of single inhibition of each isoform [36]. A dominant-negative form of VPS4 (which blocks the function of both isoforms) has also been shown to inhibit exosome secretion in RPE1 cells [37], but not in oli-neu cells which secrete exosomes in a ESCRT-independent manner [22]. Either compensation of VPS4B by increased activity of VPS4A, or alternative functions of VPS4B in HeLa cells, possibly linked to their constitutive expression of papillomavirus proteins (which have recently been shown to reduce exosome secretion [39]) could explain the observed increase of exosome secretion in our study [32].

Although many studies use ESCRT inhibition as a tool to inhibit secretion of exosomes, one should be aware that these proteins are involved in other cellular mechanisms, especially cytokinesis [29,40], and that their silencing should be examined with care since this may alter cellular functions other than the formation of MVB. In addition, ESCRT members (e.g. TSG101, ALIX, VPS4) have been shown to promote budding from the PM of enveloped viruses [40-42], or of microvesicles or exosome-like vesicles, especially in T lymphocytes [43,44]. Hence ESCRT-dependence does not necessarily demonstrate MVB origin. 


\section{b) ESCRT-independent mechanisms}

Recently, several articles suggested that ESCRT-independent mechanisms are also involved in ILV formation and exosome biogenesis: these mechanisms involve lipids, tetraspanins, or heat shock proteins. Of note, mammalian cells depleted for key ESCRT components still form MVBs [45].

Exosomes bearing the proteolipid protein (PLP) are normally secreted by oligodendroglial cells after ESCRT inhibition [22]. In these cells, inhibition of neutral sphingomyelinase, leading to impaired ceramide biogenesis, decreased exosome secretion. Ceramide was proposed to induce inward curvature of the limiting membrane of MVBs to form ILVs. Since this work, several labs have used neutral sphingomyelinase inhibition as a proof that their analysed EVs were indeed exosomes [46,47], although a potential effect of such treatments on release of PM-derived EVs, or on other cellular functions or secretions has never been actually ruled out. Caution should thus be taken in interpreting sphingomyelinase inhibition experiments.

Another lipid enriched in exosome membranes is cholesterol [20,21,23], an important component of MVBs [48]. In the same oligodendroglial cells, drugor genetic mutation-induced cholesterol accumulation in late MVBs was shown to increase the secretion of vesicles bearing Flotillin-2, ALIX, CD63 and cholesterol, in a Flotillin-2-dependent manner [49].

Finally phospholipase D2 (PLD2), which, unlike phospholipase D1 (PLD1), is enriched in exosomes [24], is involved in hydrolysis of phosphatidylcholine to phosphatidic acid (PA). PLD2, but not PLD1, was shown in two different cell types to be necessary for exosome biogenesis [24,50]. The model proposed is that PA formation in the inner leaflet of MVB's limiting membrane would induce inward curvature and thus formation of ILVs, as described for ceramide [50]. Thus, one would expect enrichment of PA in exosomes, which has not been addressed so far.

On the other hand, four-transmembrane domain proteins of the tetraspanin family have recently been proposed as instrumental in selecting cargoes for exosome secretion. In human melanoma cells, CD63 allows sorting of a melanosomal protein into ILVs, in a ceramide- and ESCRT-independent manner 
[51]. Tetraspanins are enriched in ILVs of MVBs and in exosomes [52]. TSPAN8 expression could modify both the mRNA content and the protein composition of exosomes secreted by rat pancreatic adenocarcinoma cells [53]. Similarly, CD81 was recently shown to allow targeting of an array of its ligands into secreted exosomes [54].

Finally, the chaperone HSC70 was previously shown to allow recruitment of the transferrin receptor (TFR) to exosomes [55]. More recently, cytosolic proteins containing a KFERQ-motif were found to bind HSC70, which induced their selective transfer to ILVs [56].

It is not known whether these multiple mechanisms of biogenesis of exosomes and ILVs can take place in a single MVB, or rather if they suggest that different MVBs populations can coexist within the cell. Indeed, evidence of the heterogeneity of MVBs within a single cell already exist: e.g. the non-ubiquitous distribution of cholesterol in all MVBs [57], the lack of enrichment of LBPA in exosomes, as opposed to its enrichment in ILVs [23,58], or the existence of two distinct MVB subsets within DCs, one being formed upon cognate interaction with T lymphocytes [59].

\section{Exosome secretion: transport and fusion of MVBs with the plasma} membrane

Mechanisms that drive mobilization of secretory MVBs and fusion of their limiting membrane with the PM have started being unravelled in the past few years. The studies described below are summarized in table 2 .

The RAB family of small GTPase proteins controls different steps of intracellular vesicular trafficking, such as vesicle budding, vesicle and organelle mobility through cytoskeleton interaction, and docking of vesicles to their target compartment, leading to membrane fusion [60]. Since the first proteomic studies, endosome-associated members of this family were identified in exosomes [16]. RAB11 has been linked to the control of TFR and HSC70containing exosome release in K562 cells [61]. Using different screening strategies, several RAB proteins emerged as new players in exosome secretion $[62,63]$. Inhibition of RAB35 impaired PLP-bearing exosome secretion in oli-neu cells [62], and in primary oligodendrocytes [64]. In the human cell line RPE1 
either RAB11 or RAB35 were required for the secretion of anthrax toxin-loaded exosomes to the extracellular medium [37]. In our shRNA-based screening of different RAB proteins in HeLa-CIITA cells, depletion of RAB5A, RAB9A, RAB2B, and more strikingly RAB27A and RAB27B, efficiently decreased exosome secretion, whereas depletion of RAB11A or RAB7 did not [63]. By contrast, syntenin- and ALIX-containing exosome secretion by MCF-7 cells was shown to require RAB7 [36]. The involvement of RAB27A in vesicle secretion was later confirmed in numerous tumour cell lines: murine melanoma [65] and mammary carcinoma [66], and human squamous cell carcinoma cells [35]. These RAB proteins are thought to function in MVB docking to the PM, which is required for eventual fusion of the two membranes, to allow secretion of the vesicles present in this compartment.

It is important to stress that RAB27A controls not only exosome secretion, but also the secretion of a subset of soluble factors. For instance, inhibition of RAB27A decreased secretion of the soluble pro-metastatic factor matrix metalloproteinase 9 in 4T1 mammary carcinoma cells [66], as well as pro-angiogenic placental growth factor 2, platelet-derived growth factor A and osteopontin in the B16-F10 melanoma [65]. Thus, using RAB27A inhibition alone is not sufficient to demonstrate that a physiological effect is due to exosome secretion, and therefore the possible roles of other proteins involved in secretion must be evaluated. For RAB11 and RAB35, their potential roles in secretion of soluble proteins were not analysed in the articles reporting their effects in exosome secretion $[61,62]$ and thus further work is required to clarify this.

After docking of two different intracellular compartments, soluble NSFattachment protein receptor (SNARE) complexes are instrumental in allowing fusion of the lipid bilayers [67]. The SNARE proteins SNAP-23, VAMP-7 and VAMP-8 are involved in $\mathrm{Ca}^{2+}$-regulated fusion of secretory lysosomes with the PM in different cell types [68-70]. However SNAREs do not necessarily mediate the fusion of MVBs with the PM during exosome secretion. While VAMP7 is essential for the release of acetylcholinesterase-containing EVs in K562 erythroleukemia cells [71], inhibition of VAMP7 in MDCK cells impaired lysosomal secretion but not the release of exosomes [72]. More recently, the RSNARE protein YKT6 was found to be required for secretion of exosomes 
carrying the WNT3A morphogen in HEK293 cells [34], and these results await confirmation in other models.

Again, the heterogeneity in the requirement for docking and fusion machineries could suggest the coexistence of different multivesicular compartments within the cell. RAB11 and RAB35 are described as associated with recycling and early sorting endosomes, whereas RAB27A and RAB27B are associated with the late endosomal and secretory compartments [60]. Thus, we would like to propose that different RABs are involved in docking of ILVcontaining endosomes of different maturation stages along the endosomal pathway (Figure 1). These different MVBs could give the rise to different subpopulations of small EVs. This could explain RAB27A-independent secretion of a subpopulation of vesicles from tumour cells [73], or of anthrax toxincontaining exosomes from human epithelial cells [37].

\section{Future challenges: separation of the different subtypes of exosomes}

It recently became clear that all currently used protocols for exosome purification actually co-purify different subtypes of EVs. Demonstrations of this caveat were published recently, by three independent groups [73-75] and came from the careful analysis of the behaviour of exosomes upon floatation into a sucrose gradient. Although the density of exosomes in such gradients has been described for at least a decade as ranging between 1.11 and $1.19 \mathrm{~g} / \mathrm{ml}$, recent articles show that different types of EVs are present within this range of densities. Two reports showed that some EVs in the exosome pellet display similar equilibrium densities but different kinetics to reach this density, and thus are likely compositionally different $[74,75]$. We confirmed this observation, and also showed that the vesicles equilibrating at lower density fractions $(1.11 \mathrm{~g} / \mathrm{ml})$ were less dependent on Rab27a for their secretion than those floating at 1.14 $\mathrm{g} / \mathrm{ml}$ [73] consistent with the presence of at least two subpopulations of EVs within the purified exosome population. An urgent need in the field is to ameliorate already existing protocols, or to establish new methods that will allow separate analysis of the different subsets of EVs.

In all studies published thus far, several fractions recovered after floatation of exosomes into a sucrose gradient are pooled together to study the 
presence of different exosome markers and to perform functional assays. Further improvement could be now to analyse separately the vesicles recovered in 3-5 fractions of the expected exosome density. Immuno-capture of specific subsets of vesicles has been also performed, using CD63 as a marker of MVBderived vesicles [63], or markers of the apical versus basolateral surface of polarized tumour cells [76]. Although powerful, these approaches will benefit from the future identification of specific surface markers of each subtype of EVs. Finally, polymer-based kits are now commercialized for vesicle isolation. Although this method is less laborious and time-consuming, and apparently provides a higher rate of recovery, especially of extracellular RNAs [77], we suspect that even more heterogeneous types of particles present in conditioned medium or body fluids will be recovered with this method, especially lipoproteins, and cell debris, and optimisation is still called for.

\section{Conclusions / closing remarks}

A number of discoveries in recent years have increased the interest of cell biologists in exosomes: first the confirmation of this secretory pathway within immune cells (8), then their identification in body fluids [78] hence their existence in vivo, and finally, the discovery of their nucleic acid (RNA) content [12]. These breakthroughs led to a rise in the number of exosome-related studies in the literature, but also to a general rise in interest in all types of EVs. Interestingly, so far, no universal mechanism of either biogenesis or secretion of exosomes has emerged. It remains to be determined whether the differences in mechanisms described by different groups are due to cell-intrinsic specific mechanisms of exosome formation and secretion, or to differences in the nature of the vesicles analysed. Finally, a crucial question remains unsolved: the physiological relevance of exosome and/or PM-derived vesicle release in vivo. The answers to these questions will only become possible when the outstanding cell biology issues have been solved, especially what drives the fate of MVBsfusion with the PM or with lysosomes, and how MVBs fuse with the PM. 


\section{Acknowledgements:}

We apologize to all colleagues whose work could not be extensively quoted in this short review. Exosome-related work performed in the Théry lab is supported by fundings from Institut National de la Santé et de la Recherche Médicale, Institut Curie (including fellowship to J. Kowal), Association pour la Recherche contre le Cancer (including fellowship to M. Tkach), Fondation de France, Agence Nationale de la Recherche ([ANR-10-IDEX-0001-02 PSL*] and [ANR-11-LABX-0043]). We thank Omar Vivar for critical reading and english editing of the manuscript. 


\section{Box 1: Nomenclature issue.}

Here, we use the term "exosomes" as defined by Rose Johnstone in 1987 [7], and not the more general use for any vesicles released by cells [79]. Currently, the use of the term "exosomes" for MVB-derived EVs is generally accepted in the field, although the variety of EVs secreted by cells and difficulties in proving the actual origin of EVs led to a less strict usage: either for any small EVs (of 50-100 $\mathrm{nm}$ diameter by transmission electron microscopy), or for EVs recovered after $100,000 \mathrm{~g}$ ultracentrifugation. As proposed recently by S. Gould and G. Raposo [80], given the lack of perfect demonstration of EVs' endosomal origin, we can only suggest that researchers clearly specify their interpretation of whatever term they use for the EVs they analyse. In addition, the term "exosome" has been used since 1997 in a completely different field, not related to EVs: for a multienzyme ribonuclease complex involved in RNA processing [81]. Note that the first occurrence of the term in the literature was in 1970 for an "exosome model", proposing that DNA segments enter the cells of treated individuals and become firmly associated with their homologous chromosome segments, but are never integrated into the linear structure of the chromosome [82]. « Exosome» is not used in this particular sense anymore.

\section{Figure 1: intracellular machineries of exosome biogenesis and secretion}

Schematic representation of the origin and release of exosomes by eukaryotic cells. Exosomes are formed as ILVs by budding into early endosomes and MVBs. Several molecules are involved in the biogenesis of ILVs, such as the ESCRT machinery, the lipid ceramide and the tetraspanins. It is still unknown whether these mechanisms act simultaneously on the same MVB or on different MVBs. The fate of MVBs can be either fusion with lysosomes or fusion with the PM, which allows the release of their content to the extracellular milieu. Several RAB proteins (RAB11, RAB27 and RAB35) have been shown to be involved in the transport of MVBs to the PM and in exosome secretion. Here, we propose that these proteins can act on different MVBs. In addition, SNAREs are probably involved in fusion of these MVBs with the PM. Other types of secreted vesicles bud directly from the plasma membrane, and are often called microvesicles, or micro particles, two words also sometimes used generally for all types of EVs. 


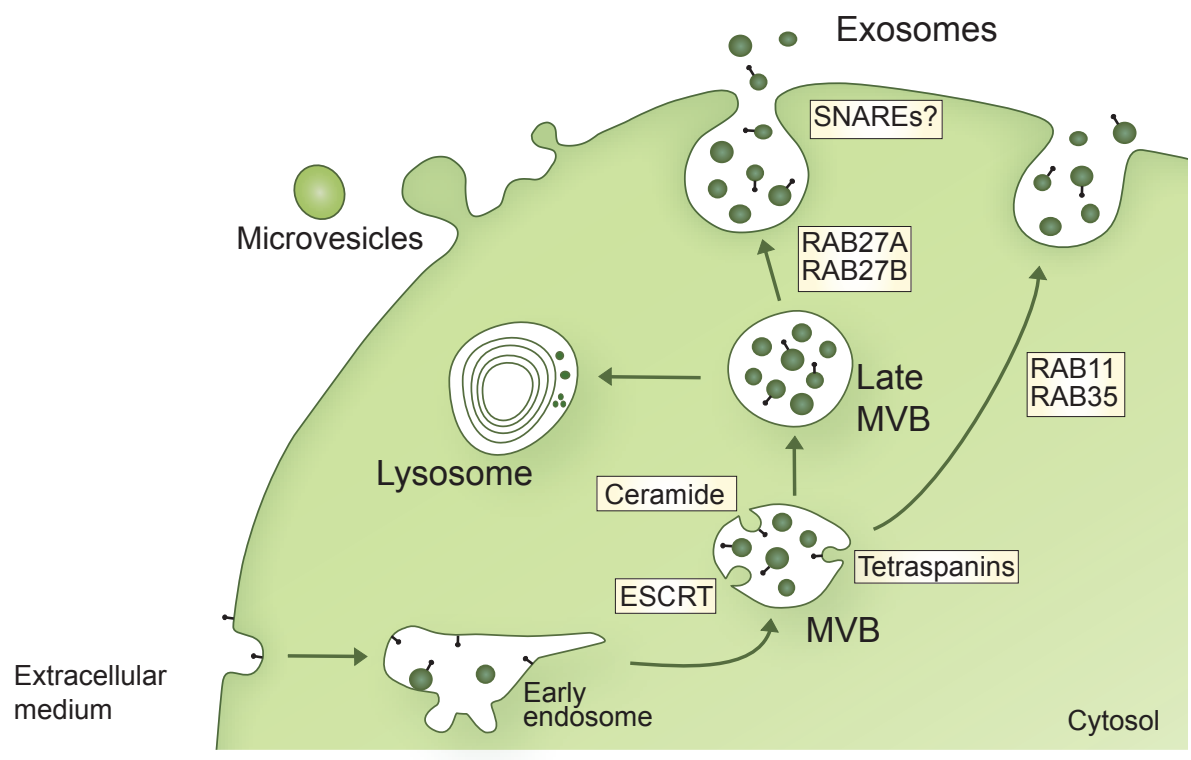


Table 1. Published studies on exosome biogenesis

(italics highlight tumour cell models)

\begin{tabular}{|c|c|c|c|c|}
\hline Protein Name & $\begin{array}{l}\text { Cell type used in } \\
\text { study }\end{array}$ & $\begin{array}{c}\text { Markers used for exosome } \\
\text { definition }\end{array}$ & $\begin{array}{l}\text { Tools used for } \\
\text { inhibition }\end{array}$ & Reference \\
\hline \multirow{4}{*}{ HRS } & HeLa-CIITA & CD63, CD81, MHCII & shRNA & [32] \\
\hline & $\begin{array}{c}\text { Primary } \\
\text { Dendritic cells }\end{array}$ & $\begin{array}{l}\text { Ubiquitinated proteins, } \\
\text { TSG101, VPS4B }\end{array}$ & shRNA & [33] \\
\hline & HEK293 & EVI, WNT3A, CD81 & siRNA & [34] \\
\hline & $\begin{array}{c}\text { Head neck } \\
\text { squamous cell } \\
\text { carcinoma } \\
(\text { SCC25-H1047R) } \\
\end{array}$ & MT1, TSG101 & siRNA & [35] \\
\hline STAM1 & HeLa-CIITA & CD63, CD81, MHCII & shRNA & {$[32]$} \\
\hline \multirow{4}{*}{ TSG101 } & HeLa-CIITA & CD63, CD81, MHCII & shRNA & [32] \\
\hline & $M C F-7$ & $\begin{array}{c}\text { Syntenin-1, CD63, } \\
\text { syndecan-1 C-terminal } \\
\text { fragment }\end{array}$ & siRNA & [36] \\
\hline & RPE1 & Flotillin-1 & siRNA & [37] \\
\hline & Oli-neu & PLP & siRNA & {$[22]$} \\
\hline 釒| & $M C F-7$ & $\begin{array}{c}\text { Syntenin-1, CD63, } \\
\text { syndecan-1 C-terminal } \\
\text { fragment }\end{array}$ & siRNA & [36] \\
\hline \multirow{3}{*}{ ALIX } & HeLa-CIITA & CD63, CD81, MHCII & shRNA & [32] \\
\hline & $M C F-7$ & $\begin{array}{c}\text { Syntenin-1, CD63, } \\
\text { syndecan-1 C-terminal } \\
\text { fragment }\end{array}$ & siRNA & [36] \\
\hline & $\mathrm{C} 2 \mathrm{C} 12$ & $\begin{array}{c}\text { ALIX, HSC70, beta enolase, } \\
\text { Pan-actin, CD63 }\end{array}$ & SiRNA & [38] \\
\hline \multirow{3}{*}{ VPS4 } & RPE1 & Flotillin-1 & $\begin{array}{c}\text { Dominant } \\
\text { negative mutant } \\
\text { overexpressed }\end{array}$ & {$[37]$} \\
\hline & HeLa-CIITA & CD63, CD81, MHCII & shRNA & [32] \\
\hline & $M C F-7$ & $\begin{array}{c}\text { Syntenin-1, CD63, } \\
\text { syndecan-1 C-terminal } \\
\text { fragment }\end{array}$ & $\begin{array}{c}\text { Inhibition of } \\
\text { both isoforms by } \\
\text { siRNA }\end{array}$ & [36] \\
\hline \multicolumn{5}{|c|}{ ESCRT-independent mechanism } \\
\hline \multirow{4}{*}{ Ceramide } & Oli-neu & PLP & $\begin{array}{c}\text { GW4869 } \\
\text { (neutral } \\
\text { sphingomyelinas } \\
\text { e inhibitor) }\end{array}$ & {$[22]$} \\
\hline & $M C F-7$ & $\begin{array}{c}\text { Syntenin-1, CD63, } \\
\text { syndecan-1 C-terminal } \\
\text { fragment }\end{array}$ & siRNA & {$[36]$} \\
\hline & Huh-7.5.1c2 & CD63, CD81 & GW4869 & [46] \\
\hline & HEK293 & CD63 & GW4869, siRNA & [47] \\
\hline Flotillin-2 & Oli-neu & $\begin{array}{c}\text { Flotillin-2, ALIX, CD63, } \\
\text { cholesterol }\end{array}$ & siRNA & [49] \\
\hline \multirow[t]{2}{*}{ PLD2 } & MCF-7 & ALIX, Syntenin-1, CD63 & $\begin{array}{c}\text { siRNA, } \\
\text { CAY10594 } \\
\text { (PLD2 inhibitor) }\end{array}$ & {$[50]$} \\
\hline & RBL-2H3 & $\begin{array}{c}\text { Fluorescent staining of } \\
\text { membranes }\end{array}$ & $\begin{array}{l}\text { Overexpression } \\
\text { of active / }\end{array}$ & [24] \\
\hline
\end{tabular}




\begin{tabular}{|l|c|c|c|c|}
\hline & & & inactive form & \\
\hline CD81 & $\begin{array}{c}\text { Primary } \\
\text { Lymphoblasts }\end{array}$ & Proteomic analysis & Knock-out mice & {$[54]$} \\
\hline
\end{tabular}

Table 2. Published studies on exosome secretion.

(italics highlight tumour cell models)

\begin{tabular}{|c|c|c|c|c|c|}
\hline \multicolumn{6}{|c|}{ RAB family } \\
\hline Name & $\begin{array}{l}\text { Major } \\
\text { intracellular } \\
\text { localization }\end{array}$ & $\begin{array}{l}\text { Cell type used } \\
\text { in the study }\end{array}$ & $\begin{array}{l}\text { Markers used for } \\
\text { vesicle definition }\end{array}$ & $\begin{array}{l}\text { Tools used } \\
\text { for } \\
\text { inhibition }\end{array}$ & Reference \\
\hline RAB2B & $\begin{array}{c}\text { Endoplasmic } \\
\text { reticulum and } \\
\text { Golgi apparatus. }\end{array}$ & HeLa-CIITA & CD63, MHC II, CD81 & shRNA & [63] \\
\hline RAB5A & Early endosomes & HeLa-CIITA & CD63, MHC II, CD81 & shRNA & [63] \\
\hline RAB7 & Late endosomes & $M C F-7$ & $\begin{array}{l}\text { CD63, Syntenin-1, } \\
\text { Syndecan } 1 \text { C- } \\
\text { Terminal Fragment }\end{array}$ & siRNA & [36] \\
\hline RAB9A & Late endosomes & HeLa-CIITA & CD63, MHC II, CD81 & shRNA & [63] \\
\hline \multirow[t]{2}{*}{ RAB11 } & \multirow[t]{2}{*}{$\begin{array}{l}\text { Recycling and } \\
\text { early sorting } \\
\text { endosomes }\end{array}$} & K562 & $\begin{array}{c}\text { TFR, HSC70, } \\
\text { Acetylcholinesteras } \\
\text { e activity }\end{array}$ & $\begin{array}{c}\text { Dominant } \\
\text { negative } \\
\text { mutant } \\
\text { overexpress } \\
\text { ion }\end{array}$ & [61] \\
\hline & & RPE1 & $\begin{array}{l}\text { Flotillin-1, Anthrax } \\
\text { Toxin Lethal Factor }\end{array}$ & SiRNA & [37] \\
\hline \multirow{4}{*}{ RAB27A } & \multirow{4}{*}{$\begin{array}{l}\text { Late endosomes } \\
\text { and lysosome- } \\
\text { related } \\
\text { organelles }\end{array}$} & HeLa-CIITA & CD63, MHC II, CD81 & shRNA & [63] \\
\hline & & $4 T 1, T S / A$ & $\begin{array}{c}\text { ALIX, HSC70, CD63, } \\
\text { TSG101 }\end{array}$ & shRNA & [66] \\
\hline & & $\begin{array}{c}\text { B16-F10, SK- } \\
\text { Mel-28 }\end{array}$ & ALIX, TSG101 & shRNA & [65] \\
\hline & & $\begin{array}{c}\text { SCC61, SCC25- } \\
H 1047 R\end{array}$ & - & shRNA & [35] \\
\hline RAB27B & $\begin{array}{l}\text { Late endosomes } \\
\text { and lysosome- } \\
\text { related } \\
\text { organelles } \\
\end{array}$ & HeLa-CIITA & CD63, MHC II, CD81 & shRNA & [63] \\
\hline \multirow[t]{3}{*}{ RAB35 } & \multirow[t]{3}{*}{$\begin{array}{l}\text { Recycling } \\
\text { endosomes }\end{array}$} & Oli-neu & PLP & $\begin{array}{c}\text { siRNA and } \\
\text { dominant } \\
\text { negative } \\
\text { mutant } \\
\text { overexpress } \\
\text { ion } \\
\end{array}$ & [62] \\
\hline & & RPE1 & Flotillin-1 & siRNA & [37] \\
\hline & & $\begin{array}{c}\text { Primary } \\
\text { oligodendrocyt } \\
\text { es } \\
\end{array}$ & ALIX, PLP & siRNA & [64] \\
\hline \multicolumn{6}{|c|}{ SNARE family } \\
\hline VAMP7 & $\begin{array}{l}\text { Lysosomes and } \\
\text { late endosomes }\end{array}$ & K562 & $\begin{array}{l}\text { Acetylcholinesteras } \\
\text { e activity }\end{array}$ & $\begin{array}{c}\text { Truncated } \\
\text { VAMP7 } \\
\text { overexpress } \\
\text { ion } \\
\end{array}$ & [71] \\
\hline YKT6 & $\begin{array}{l}\text { Early and } \\
\text { recycling } \\
\text { endosomes }\end{array}$ & HEK293 & WNT3A, CD81 & siRNA & [34] \\
\hline
\end{tabular}




\section{References}

1. Crawford N: The presence of contractile proteins in platelet microparticles isolated from human and animal platelet-free plasma. Br J Haematol 1971, 21:53-69.

2. Dvorak HF, Quay SC, Orenstein NS, Dvorak AM, Hahn P, Bitzer AM, Carvalho AC: Tumor shedding and coagulation. Science 1981, 212:923-924.

3. Anderson HC: Vesicles associated with calcification in the matrix of epiphyseal cartilage. J Cell Biol 1969, 41:59-72.

4. Stegmayr B, Ronquist G: Promotive effect on human sperm progressive motility by prostasomes. Urol Res 1982, 10:253-257.

5. Pan BT, Teng K, Wu C, Adam M, Johnstone RM: Electron microscopic evidence for externalization of the transferrin receptor in vesicular form in sheep reticulocytes. J Cell Biol 1985, 101:942-948.

6. Harding C, Heuser J, Stahl P: Receptor-mediated endocytosis of transferrin and recycling of the transferrin receptor in rat reticulocytes. J Cell Biol 1983, 97:329-339.

7. Johnstone RM, Adam M, Hammond JR, Orr L, Turbide C: Vesicle formation during reticulocyte maturation. Association of plasma membrane activities with released vesicles (exosomes). J Biol Chem 1987, 262:94129420.

8. Raposo G, Nijman HW, Stoorvogel W, Liejendekker R, Harding CV, Melief CJ, Geuze HJ: B lymphocytes secrete antigen-presenting vesicles. J Exp Med 1996, 183:1161-1172.

*This paper presents the first evidence that antigen presenting cells secrete MHC class II-containing exosomes, which are able to induce antigen-specific MHC class II-restricted $T$ cell responses, suggesting a signaling, rather than "garbage", role for exosomes.

9. Zitvogel L, Regnault A, Lozier A, Wolfers J, Flament C, Tenza D, RicciardiCastagnoli P, Raposo G, Amigorena S: Eradication of established murine tumors using a novel cell-free vaccine: dendritic cell-derived exosomes. Nat Med 1998, 4:594-600.

10. van Niel G, Raposo G, Candalh C, Boussac M, Hershberg R, Cerf-Bensussan N, Heyman M: Intestinal epithelial cells secrete exosome-like vesicles. Gastroenterology 2001, 121:337-349.

11. Wolfers J, Lozier A, Raposo G, Regnault A, Thery C, Masurier C, Flament C, Pouzieux S, Faure F, Tursz T, et al.: Tumor-derived exosomes are a source of shared tumor rejection antigens for CTL cross-priming. Nat Med 2001, 7:297-303.

12. Valadi H, Ekstrom K, Bossios A, Sjostrand M, Lee JJ, Lotvall JO: Exosomemediated transfer of mRNAs and microRNAs is a novel mechanism of genetic exchange between cells. Nat Cell Biol 2007, 9:654-659.

** This article is the first to report the presence of RNA inside exosomes, both mRNA and microRNA. The authors demonstrate that one mRNA can be transmitted to another cell through vesicles, and transcribed in the recipient cell, suggesting a novel mechanism of cell-cell communication.

13. Ratajczak J, Miekus K, Kucia M, Zhang J, Reca R, Dvorak P, Ratajczak MZ: Embryonic stem cell-derived microvesicles reprogram hematopoietic progenitors: evidence for horizontal transfer of mRNA and protein delivery. Leukemia 2006, 20:847-856. 
14. Raposo G, Stoorvogel W: Extracellular vesicles: exosomes, microvesicles, and friends. J Cell Biol 2013, 200:373-383.

15. Colombo M, Raposo G, Thery C: Biogenesis, Secretion and intercellular interactions of exosomes and other extracellular vesicles. Annual Rev Cell Dev Biol 2014, in press.

16. Thery C, Boussac M, Veron P, Ricciardi-Castagnoli P, Raposo G, Garin J, Amigorena S: Proteomic analysis of dendritic cell-derived exosomes: a secreted subcellular compartment distinct from apoptotic vesicles. $J$ Immunol 2001, 166:7309-7318.

17. Kalra $\mathrm{H}$, Simpson RJ, Ji H, Aikawa E, Altevogt $\mathrm{P}$, Askenase $\mathrm{P}$, Bond VC, Borràs FE, Breakefield X, Budnik V, et al.: Vesiclepedia: A Compendium for Extracellular Vesicles with Continuous Community Annotation. PLoS Biol 2012, 10:e1001450.

*This paper, like [18], reports the creation of a database compiling lipid, RNA, and protein data from different classes of eukaryotic EVs from the studies published over the past several years. The idea is to promote a continuous update of the database by the authors, before and after publication of their articles.

18. Kim DK, Kang B, Kim OY, Choi DS, Lee J, Kim SR, Go G, Yoon YJ, Kim JH, Jang SC, et al.: EVpedia: an integrated database of high-throughput data for systemic analyses of extracellular vesicles. J Extracell Vesicles 2013, $2: 20384$.

*Similarly to [17], this article presents an integrated database of highthroughput datasets from vesicular components, including proteins, mRNAs, miRNAs, and lipids. Here, both prokaryotic and eukaryotic EVs are included.

19. Brouwers JF, Aalberts M, Jansen JW, van Niel G, Wauben MH, Stout TA, Helms JB, Stoorvogel W: Distinct lipid compositions of two types of human prostasomes. Proteomics 2013, 13:1660-1666.

20. Laulagnier K, Motta C, Hamdi S, Roy S, Fauvelle F, Pageaux JF, Kobayashi T, Salles JP, Perret B, Bonnerot C, et al.: Mast cell- and dendritic cell-derived exosomes display a specific lipid composition and an unusual membrane organization. Biochem J 2004, 380:161-171.

21. Llorente A, Skotland T, Sylvanne T, Kauhanen D, Rog T, Orlowski A, Vattulainen I, Ekroos K, Sandvig K: Molecular lipidomics of exosomes released by PC-3 prostate cancer cells. Biochim Biophys Acta 2013, 1831:1302-1309.

22. Trajkovic K, Hsu C, Chiantia S, Rajendran L, Wenzel D, Wieland F, Schwille P, Brugger B, Simons M: Ceramide triggers budding of exosome vesicles into multivesicular endosomes. Science 2008, 319:1244-1247.

** This article was the first to describe an ESCRT-independent pathway for exosome biogenesis, requiring the sphingolipid ceramide.

23. Wubbolts R, Leckie RS, Veenhuizen PT, Schwarzmann G, Mobius W, Hoernschemeyer J, Slot JW, Geuze HJ, Stoorvogel W: Proteomic and biochemical analyses of human B cell-derived exosomes. Potential implications for their function and multivesicular body formation. J Biol Chem 2003, 278:10963-10972.

24. Laulagnier K, Grand D, Dujardin A, Hamdi S, Vincent-Schneider H, Lankar D, Salles JP, Bonnerot C, Perret B, Record M: PLD2 is enriched on exosomes 
and its activity is correlated to the release of exosomes. FEBS Lett 2004, 572:11-14.

25. Matsuo H, Chevallier J, Mayran N, Le Blanc I, Ferguson C, Faure J, Blanc NS, Matile S, Dubochet J, Sadoul R, et al.: Role of LBPA and Alix in multivesicular liposome formation and endosome organization. Science 2004, 303:531-534.

26. Ikonen E: Roles of lipid rafts in membrane transport. Curr Opin Cell Biol 2001, 13:470-477.

27. Tan SS, Yin Y, Lee T, Lai RC, Yeo RW, Zhang B, Choo A, Lim SK: Therapeutic MSC exosomes are derived from lipid raft microdomains in the plasma membrane. J Extracell Vesicles 2013, 2:22614.

28. Klumperman J, Raposo G: The complex ultrastructure of the endolysosomal system. Cold Spring Harb Perspect Biol 2014, in press.

29. Henne WM, Stenmark H, Emr SD: Molecular mechanisms of the membrane sculpting ESCRT pathway. Cold Spring Harb Perspect Biol 2013, 5.

30. Katzmann DJ, Babst M, Emr SD: Ubiquitin-dependent sorting into the multivesicular body pathway requires the function of a conserved endosomal protein sorting complex, ESCRT-I. Cell 2001, 106:145-155.

31. Hanson PI, Cashikar A: Multivesicular body morphogenesis. Annu Rev Cell Dev Biol 2012, 28:337-362.

32. Colombo M, Moita C, van Niel G, Kowal J, Vigneron J, Benaroch P, Manel N, Moita LF, Thery C, Raposo G: Analysis of ESCRT functions in exosome biogenesis, composition and secretion highlights the heterogeneity of extracellular vesicles. J Cell Sci 2013, 126:5553-5565.

33. Tamai K, Tanaka N, Nakano T, Kakazu E, Kondo Y, Inoue J, Shiina M, Fukushima K, Hoshino T, Sano K, et al.: Exosome secretion of dendritic cells is regulated by Hrs, an ESCRT-0 protein. Biochem Biophys Res Commun 2010, 399:384-390.

34. Gross JC, Chaudhary V, Bartscherer K, Boutros M: Active Wnt proteins are secreted on exosomes. Nat Cell Biol 2012, 14:1036-1045.

35. Hoshino D, Kirkbride KC, Costello K, Clark ES, Sinha S, Grega-Larson N, Tyska MJ, Weaver AM: Exosome Secretion Is Enhanced by Invadopodia and Drives Invasive Behavior. Cell Rep 2013.

36. Baietti MF, Zhang Z, Mortier E, Melchior A, Degeest G, Geeraerts A, Ivarsson Y, Depoortere F, Coomans C, Vermeiren E, et al.: Syndecan-syntenin-ALIX regulates the biogenesis of exosomes. Nat Cell Biol 2012, 14:677-685.

* This paper reveals an ESCRT-dependent mechanism for ILV/exosome formation, involving the connection of transmembrane proteoglycan receptor syndecans with syntenin and through syntenin with ALIX.

37. Abrami L, Brandi L, Moayeri M, Brown MJ, Krantz BA, Leppla SH, van der Goot FG: Hijacking multivesicular bodies enables long-term and exosomemediated long-distance action of anthrax toxin. Cell Rep 2013, 5:986-996.

** This paper shows hijacking of the exosome machinery by anthrax toxin: the toxin is protected from degradation by targeting into the lumen of ILVs in endosomes, which allows a long-term delivery to the cytosol. ILVs containing anthrax toxin can also be released to the extracellular space as exosomes, where they can be incorporated by recipient cells allowing a long-range action of the toxin. 
38. Romancino DP, Paterniti G, Campos Y, De Luca A, Di Felice V, d'Azzo A, Bongiovanni A: Identification and characterization of the nano-sized vesicles released by muscle cells. FEBS Lett 2013, 587:1379-1384.

39. Honegger A, Leitz J, Bulkescher J, Hoppe-Seyler K, Hoppe-Seyler F: Silencing of human papillomavirus (HPV) E6/E7 oncogene expression affects both the contents and the amounts of extracellular microvesicles released from HPV-positive cancer cells. Int J Cancer 2013, 133:1631-1642.

40. Bissig C, Gruenberg J: ALIX and the multivesicular endosome: ALIX in Wonderland. Trends Cell Biol 2014, 24:19-25.

41. Garrus JE, von Schwedler UK, Pornillos OW, Morham SG, Zavitz KH, Wang HE, Wettstein DA, Stray KM, Cote M, Rich RL, et al.: Tsg101 and the vacuolar protein sorting pathway are essential for HIV-1 budding. Cell 2001, 107:55-65.

42. Pornillos O, Higginson DS, Stray KM, Fisher RD, Garrus JE, Payne M, He GP, Wang HE, Morham SG, Sundquist WI: HIV Gag mimics the Tsg101recruiting activity of the human Hrs protein. J Cell Biol 2003, 162:425434.

43. Booth AM, Fang Y, Fallon JK, Yang JM, Hildreth JE, Gould SJ: Exosomes and HIV Gag bud from endosome-like domains of the T cell plasma membrane. J Cell Biol 2006, 172:923-935.

44. Choudhuri K, Llodra J, Roth EW, Tsai J, Gordo S, Wucherpfennig KW, Kam LC, Stokes DL, Dustin ML: Polarized release of T-cell-receptor-enriched microvesicles at the immunological synapse. Nature 2014.

45. Stuffers S, Sem Wegner C, Stenmark H, Brech A: Multivesicular endosome biogenesis in the absence of ESCRTs. Traffic 2009, 10:925-937.

46. Dreux M, Garaigorta U, Boyd B, Decembre E, Chung J, Whitten-Bauer C, Wieland S, Chisari FV: Short-range exosomal transfer of viral RNA from infected cells to plasmacytoid dendritic cells triggers innate immunity. Cell Host Microbe 2012, 12:558-570.

47. Kosaka N, Iguchi H, Yoshioka Y, Takeshita F, Matsuki Y, Ochiya T: Secretory mechanisms and intercellular transfer of microRNAs in living cells. J Biol Chem 2010, 285:17442-17452.

48. Hornick CA, Hamilton RL, Spaziani E, Enders GH, Havel RJ: Isolation and characterization of multivesicular bodies from rat hepatocytes: an organelle distinct from secretory vesicles of the Golgi apparatus. J Cell Biol 1985, 100:1558-1569.

49. Strauss K, Goebel C, Runz H, Mobius W, Weiss S, Feussner I, Simons M, Schneider A: Exosome secretion ameliorates lysosomal storage of cholesterol in Niemann-Pick type C disease. J Biol Chem 2010, 285:2627926288.

50. Ghossoub R, Lembo F, Rubio A, Gaillard CB, Bouchet J, Vitale N, Slavik J, Machala M, Zimmermann P: Syntenin-ALIX exosome biogenesis and budding into multivesicular bodies are controlled by ARF6 and PLD2. Nat Commun 2014, 5:3477.

* As follow-up of [35], this article unravels a new step in the ILV formation machinery, involving the small GTPase ARF6 which, by activating phospholipase D2, leads to formation of phosphatidic acid, a lipid proposed to allow inward curvature of the limiting membrane of MVBs. 
51. van Niel G, Charrin S, Simoes S, Romao M, Rochin L, Saftig P, Marks MS, Rubinstein E, Raposo G: The tetraspanin CD63 regulates ESCRTindependent and -dependent endosomal sorting during melanogenesis. Dev Cell 2011, 21:708-721.

** This paper shows for the first time a tetraspanin-dependent and ESCRTindependent mechanism of cargo sorting into ILVs. ESCRT complex is necessary for disposal of the remaining cargo by targeting to lysosomal degradation.

52. Escola JM, Kleijmeer MJ, Stoorvogel W, Griffith JM, Yoshie O, Geuze HJ: Selective enrichment of tetraspan proteins on the internal vesicles of multivesicular endosomes and on exosomes secreted by human Blymphocytes. J Biol Chem 1998, 273:20121-20127.

53. Nazarenko I, Rana S, Baumann A, McAlear J, Hellwig A, Trendelenburg M, Lochnit G, Preissner KT, Zoller M: Cell surface tetraspanin Tspan8 contributes to molecular pathways of exosome-induced endothelial cell activation. Cancer Res 2010, 70:1668-1678.

54. Perez-Hernandez D, Gutierrez-Vazquez C, Jorge I, Lopez-Martin S, Ursa A, Sanchez-Madrid F, Vazquez J, Yanez-Mo M: The Intracellular Interactome of Tetraspanin-enriched Microdomains Reveals Their Function as Sorting Machineries toward Exosomes. J Biol Chem 2013, 288:11649-11661.

* Using extensive mass spectrometry, this article shows a crucial function of the tetraspanin CD81 in sorting its interacting partners into exosomes.

55. Geminard C, De Gassart A, Blanc L, Vidal M: Degradation of AP2 during reticulocyte maturation enhances binding of hsc70 and Alix to a common site on TFR for sorting into exosomes. Traffic 2004, 5:181-193.

56. Sahu R, Kaushik S, Clement CC, Cannizzo ES, Scharf B, Follenzi A, Potolicchio I, Nieves E, Cuervo AM, Santambrogio L: Microautophagy of cytosolic proteins by late endosomes. Dev Cell 2011, 20:131-139.

57. Mobius W, Ohno-Iwashita Y, van Donselaar EG, Oorschot VM, Shimada Y, Fujimoto T, Heijnen HF, Geuze HJ, Slot JW: Immunoelectron microscopic localization of cholesterol using biotinylated and non-cytolytic perfringolysin 0.J Histochem Cytochem 2002, 50:43-55.

58. White IJ, Bailey LM, Aghakhani MR, Moss SE, Futter CE: EGF stimulates annexin 1-dependent inward vesiculation in a multivesicular endosome subpopulation. EMBO J 2006, 25:1-12.

59. Buschow SI, Nolte-'t Hoen EN, van Niel G, Pols MS, ten Broeke T, Lauwen M, Ossendorp F, Melief CJ, Raposo G, Wubbolts R, et al.: MHC II in dendritic cells is targeted to lysosomes or $\mathrm{T}$ cell-induced exosomes via distinct multivesicular body pathways. Traffic 2009, 10:1528-1542.

60. Stenmark H: Rab GTPases as coordinators of vesicle traffic. Nat Rev Mol Cell Biol 2009, 10:513-525.

61. Savina A, Fader CM, Damiani MT, Colombo MI: Rab11 promotes docking and fusion of multivesicular bodies in a calcium-dependent manner. Traffic 2005, 6:131-143.

62. Hsu C, Morohashi Y, Yoshimura S, Manrique-Hoyos N, Jung S, Lauterbach MA, Bakhti M, Gronborg M, Mobius W, Rhee J, et al.: Regulation of exosome secretion by Rab35 and its GTPase-activating proteins TBC1D10A-C. J Cell Biol 2010, 189:223-232.

** One (with [63]) of two medium-scale screening strategies to identify molecular machineries of exosome secretion, showing a role for Rab 
proteins. The authors used a library of GTPase Activating Proteins in olineu cells, and thus identified TBC1D10 family and its target Rab35 as crucial for secretion of exosomes bearing PLP.

63. Ostrowski M, Carmo NB, Krumeich S, Fanget I, Raposo G, Savina A, Moita CF, Schauer K, Hume AN, Freitas RP, et al.: Rab27a and Rab27b control different steps of the exosome secretion pathway. Nat Cell Biol 2010, 12:19-30; sup pp 11-13.

** Screening strategy as in [62], but using a library of shRNA specific for RAB proteins, in HeLa-CIITA cells. RAB27A and RAB27B were identified as crucial for secretion of CD63- and MHC class II- or CD81-containing exosomes.

64. Fruhbeis C, Frohlich D, Kuo WP, Amphornrat J, Thilemann S, Saab AS, Kirchhoff F, Mobius W, Goebbels S, Nave KA, et al.: Neurotransmittertriggered transfer of exosomes mediates oligodendrocyte-neuron communication. PLoS Biol 2013, 11:e1001604.

65. Peinado H, Aleckovic M, Lavotshkin S, Matei I, Costa-Silva B, Moreno-Bueno G, Hergueta-Redondo M, Williams C, Garcia-Santos G, Ghajar C, et al.: Melanoma exosomes educate bone marrow progenitor cells toward a prometastatic phenotype through MET. Nat Med 2012, 18:883-891.

* Like [66], this article addresses the function of exosome secretion by tumors in vivo, and shows a prometastatic effect of melanoma exosomes acting as a mediators between tumor cells and bone marrow progenitors. Of note, the authors use Rab27a depletion to decrease exosome secretion, and like in [66], they show that not only exosome, but also soluble factors require Rab27a for efficient secretion.

66. Bobrie A, Krumeich S, Reyal F, Recchi C, Moita LF, Seabra MC, Ostrowski M, Thery C: Rab27a supports exosome-dependent and -independent mechanisms that modify the tumor microenvironment and can promote tumor progression. Cancer Res 2012, 72:4920-4930.

* Study similar to [66] in a murine breast cancer cell model. A role of exosomes, together with secreted soluble factors, in recruiting protumoral neutrophils to the tumor is shown. Here also, Rab27a depletion inhibits secretion not only of exosomes, but also of some soluble factors.

67. Zylbersztejn K, Galli T: Vesicular traffic in cell navigation. FEBS J 2011, 278:4497-4505.

68. Rao SK, Huynh C, Proux-Gillardeaux V, Galli T, Andrews NW: Identification of SNAREs involved in synaptotagmin VII-regulated lysosomal exocytosis. $J$ Biol Chem 2004, 279:20471-20479.

69. Tiwari N, Wang CC, Brochetta C, Ke G, Vita F, Qi Z, Rivera J, Soranzo MR, Zabucchi G, Hong W, et al.: VAMP-8 segregates mast cell-preformed mediator exocytosis from cytokine trafficking pathways. Blood 2008, 111:3665-3674.

70. Puri N, Roche PA: Mast cells possess distinct secretory granule subsets whose exocytosis is regulated by different SNARE isoforms. Proc Natl Acad Sci U $S$ A 2008, 105:2580-2585.

71. Fader CM, Sanchez DG, Mestre MB, Colombo MI: TI-VAMP/VAMP7 and VAMP3/cellubrevin: two v-SNARE proteins involved in specific steps of the autophagy/multivesicular body pathways. Biochim Biophys Acta 2009, 1793:1901-1916. 
72. Proux-Gillardeaux V, Raposo G, Irinopoulou T, Galli T: Expression of the Longin domain of TI-VAMP impairs lysosomal secretion and epithelial cell migration. Biol Cell 2007, 99:261-271.

73. Bobrie A, Colombo M, Krumeich S, Raposo G, Thery C: Diverse subpopulations of vesicles secreted by different intracellular mechanisms are present in exosome preparations obtained by differential ultracentrifugation. J Extracell Vesicles 2012, 1: 18397.

** One of three studies (with [74, 75]) showing the co-secretion of different subtypes of exosomes. Here, inhibition of Rab27a in a mouse tumor breast cell line leads to inhibition of secretion of vesicles bearing some classical exosome markers, while vesicles bearing another subset of exosome markers remained abundant. Flotation on sucrose gradient shows different floatation behaviours of these different markers.

74. Aalberts M, van Dissel-Emiliani FM, van Adrichem NP, van Wijnen M, Wauben $\mathrm{MH}$, Stout TA, Stoorvogel W: Identification of distinct populations of prostasomes that differentially express prostate stem cell antigen, annexin A1, and GLIPR2 in humans. Biol Reprod 2012, 86:82.

** Like $[73,75]$, this study unravels the heterogenity of vesicles present in human seminal fluids. Here, floatation of the vesicles on sucrose gradient reveals the existence of vesicles of similar equilibrium densities, but reaching this equilibrium with different kinetics.

75. Palma J, Yaddanapudi SC, Pigati L, Havens MA, Jeong S, Weiner GA, Weimer KM, Stern B, Hastings ML, Duelli DM: MicroRNAs are exported from malignant cells in customized particles. Nucleic Acids Res 2012, 40:91259138.

** Study similar to $[73,74]$, analysing vesicles secreted by human breast cancer cells. The authors show that different miRNA are associated with distinct subpopulations of EVs, which achieve density equilibrium at different time points.

76. Tauro BJ, Greening DW, Mathias RA, Mathivanan S, Ji H, Simpson RJ: Two Distinct Populations of Exosomes Are Released from LIM1863 Colon Carcinoma Cell-derived Organoids. Mol Cell Proteomics 2013, 12:587-598.

77. Taylor DD, Zacharias W, Gercel-Taylor C: Exosome isolation for proteomic analyses and RNA profiling. Methods Mol Biol 2011, 728:235-246.

78. Andre F, Schartz NE, Movassagh M, Flament C, Pautier P, Morice P, Pomel C, Lhomme C, Escudier B, Le Chevalier T, et al.: Malignant effusions and immunogenic tumour-derived exosomes. Lancet 2002, 360:295-305.

79. Trams EG, Lauter CJ, Salem N, Jr., Heine U: Exfoliation of membrane ectoenzymes in the form of micro-vesicles. Biochim Biophys Acta 1981, 645:63-70.

80. Gould SJ, Raposo G: As we wait: coping with an imperfect nomenclature for extracellular vesicles. J Extracell Vesicles 2013, 2:20389.

** Recent discussion of the difficulties in the current use of nomenclature for EVs. This article is a very simple and informative guide for all scientists involved in EV research, as well as an important reading for beginners.

81. Mitchell P, Petfalski E, Shevchenko A, Mann M, Tollervey D: The exosome: a conserved eukaryotic RNA processing complex containing multiple 3'-->5' exoribonucleases. Cell 1997, 91:457-466.

82. Fox AS, Yoon SB: DNA-induced transformation in Drosophila: locusspecificity and the establishment of transformed stocks. Proc Natl Acad Sci U S A 1970, 67:1608-1615. 